\title{
Futebol e sociabilidade: faces tradicionais e modernas de um clube de futebol
}

\author{
José Luiz dos Anjos* \\ Juliana Guimarães Saneto** \\ Otavio Guimarães Tavares ${ }^{* * *}$
}

\begin{abstract}
Resumo: O estudo analisou a navegabilidade social de exjogadores de futebol de um clube de associados, predominantemente formado por policiais militares e civis. Foram discutidas as categorias hierarquia, pessoa e indivíduo, tomando como fonte teórica Dumont (1993). As informações para análises foram colhidas em entrevistas abertas com jogadores de futebol do clube, no período de 1970-76. Concluise que o clube se organiza estruturalmente como uma instituição moderna com seu estatuto e instâncias burocráticas, mas se move tradicionalmente. As relações sociais dos atores permitiram identificar uma navegabilidade social amparada na pessoa, patrocinada pelo desempenho por ter sido jogador de futebol.
\end{abstract}

Palavras-chave: Futebol. Hierarquia social. Pessoas. Indivídualidade.

\section{INTRODUÇÃo}

Uma das questões mais importantes para a teoria social moderna refere-se às relações entre indivíduo e sociedade. A partir de teorizações iniciadas ainda no século XIX por Durkheim, de maneira mais particular, autores como Marcel Mauss (2003), Radcliffe-Brown (1973), Louis Dumont (1993) e Roberto DaMatta (1990) se dedicaram a discutir como se estrutura socialmente uma instituição

\footnotetext{
'Departamento de desportos. Programa de Pós-graduação em educação física. Universidade Federal do Espírito Santo, Vitória, ES, Brasil. .E-mail: jluanjos1@hotmail.com

"Programa de Pós-graduação em educação física. Universidade Federal do Espírito Santo. Vitória, ES, Brasil E-mail: jsaneto@yahoo.com.br

"'Programa de Pós-graduação em educação física. Universidade Federal do Espírito Santo. Vitória, ES, Brasil E-mail:tavaresotavio@yahoo.com.
} 
social: no indivíduo ou na pessoa? Para a Educação Física, essa temática inaugura um novo ângulo de observação das relações sociais presentes nas organizações esportivas, por exemplo.

O objetivo deste estudo é identificar as características das relações sociais de um clube voltado eminentemente para o futebol. A questão que norteia a problemática é a análise de como se apresentam os atores nas relações sociais estruturadas na vida social de um clube associativo civil, mas cujos sócios eram eminentemente oriundos de corporações militares, que tem o futebol como elemento substancial que promove as relações.

Quanto à escolha dos métodos de investigação, realizamos uma pesquisa de campo, coletando informações com os atores que fizeram parte do cenário das relações sociais e foram ativos na participação da equipe de futebol do clube e analisando documentos do clube. Realizamos entrevistas abertas com sete sujeitos, todos ex-jogadores de futebol, pertencentes ao time titular, dos anos idos de 1970 a 1976, período áureo do clube, segundo seus documentos. Preliminarmente, a proposta era entrevistar os onze jogadores titulares que finalizaram a disputa do campeonato de futebol de 1970, denominado "Cidade de Vitória". Realizamos contatos com a diretoria do clube, ocasião em que foi possível fornecer os nomes dos jogadores da época. Contamos com a colaboração de sete informantes/sujeitos, haja vista que três ex-jogadores estavam residindo em outro Estado e um havia falecido. Os encontros ocorreram na própria residência dos entrevistados.

$\mathrm{Na}$ análise e citação dos discursos dos entrevistados, utilizamos as siglas A1, A2... e A7, para identificar os sujeitos, de modo a preservar a identidade dos informantes. A idade dos sujeitos, na data das entrevistas, oscilava entre 61 e 74 anos. Todos estavam aposentados. As entrevistas se pautaram nas relações entre os jogadores da equipe de futebol, em suas relações com as esferas hierárquicas da Corporação e com grupos sociais a qualidade de jogadores de futebol.

No que se refere aos documentos, adotamos como critério a seleção de fontes que pudessem, direta ou indiretamente, fornecer 
pistas e dados sobre as maneiras instituídas pelas quais se estruturavam as relações entre os membros do clube. Em face do precário estado de preservação de arquivos do clube, a fonte principal de nossa pesquisa foi o Estatuto do clube, aprovado em 1970 pelo Conselho Deliberativo e vigente até 2007.

Levantamos a discussão em torno de duas categorias: indivíduo e pessoa, procurando articular suas características em cada momento de sociabilidade. Também procuramos apresentar os fundamentos antropológicos dessas categorias, discutindo-as com uma terceira, hierarquia.

Para discutirmos as categorias elencadas, procuramos nos amparar em Foucault (2010) e Weber (1982) e suas teorizações sobre poder e burocracia nas instituições modernas. A burocracia envolve uma hierarquia de autoridade clara e influencia significativamente nas relações sociais. Comparativamente, Dumont (1993) e DaMatta (1991 e 1998) nos fornecem elementos teóricos de uma mesma matriz, a antropologia social. Dumont, tendo como metodologia a análise comparativa entre a sociedade ocidental moderna e a tradicional, permite-nos conhecer melhor o sistema de ideias e valores da configuração individualista. Por sua vez, DaMatta nos revela o lado autoritário e hierarquizado da sociedade brasileira baseada em uma ordem formal, de posições de status e prestígio social.

Para o processo analítico nas duas situações, utilizamos a Análise do Discurso, conforme Maingueneau (1998). Analisar documentos juntamente com as falas de grupos sociais possibilita ao pesquisador aproximar-se da realidade histórica social, contudo a fala deve ser problematizada, pois os sujeitos revelam a interpretação da realidade, não constituindo, portanto, em verdade absoluta, mas em uma visão relacionada com a posição política e ideológica de quem narra, pois quem relata escolhe o que deve ou não ser lembrado. Portanto as falas são de origem subjetiva, traduzindo uma construção ideológica da realidade.

Vemos necessidade de nos dirigir pela denotação, ou seja, a ação discursiva que aponta a posição política e ideológica das 
narrativas. Na análise, lançamos as seguintes questões: quais as condições de produção do discurso a ser analisado? (a instituição na qual ele se inscreve, as representações que interferem em sua construção e a conjuntura política existente nas relações de força o que nos motivou a analisar o estatuto do Caxias Esporte Clube (CEC) e, num segundo momento, questionar: "quem produziu o discurso?" Nesse caso, devemos atentar tanto para a inserção política do sujeito que está elaborando o discurso quanto para as intenções e os resultados visados. A confrontação das narrativas será com a literatura articulada pelos pesquisadores.

Por fim, vale destacar que apesar do lócus da análise estar situado um clube civil constituído por militares, em pleno período da ditadura militar no Brasil (1964-1985), no qual o primado da hierarquia militar seria um princípio fundamental inquebrantável transposto de modo intocado para o clube, partimos de um princípio epistemológico que supera a possibilidade de uma relação mecânica de sobredeterminação das estruturas sociais em relação as ações dos indivíduos em favor da concepção da história como movimento contraditório e a sociedade como lugar de consenso e conflito. Apesar da inexistência de outras pesquisas sobre o mesmo tema específico, acompanhamos as conclusões evidenciadas nos estudos de D'Araujo et al. (1994) e Sodré (1997), por exemplo, a respeito das tensões e divergências existentes nas Forças Armadas naquele período, indicando a possibilidade de configuração de formas particulares de correlação de forças. O mesmo foi evidenciado por Taborda de Oliveira (2003) em suas análises a respeito das concepções de educação física veiculadas na Revista Brasileira de Educação Física e Desportos, periódico editado pelo Ministério da Educação entre 1968 e 1984. Isto demonstra que existe sustentação histórica para pensarmos na validade das teorias antropológicas aqui mobilizadas para pensarmos as relações sociais hierárquicas. 


\section{Caminhos e debates teóRICOS: hIERARQUIA, PESSOA E INDIVÍDUO}

Entre diversos aportes da antropologia social, nos estudos das relações sociais, o cenário aponta para uma relativização da noção de pessoa em meio aos grupos sociais e institucionais. Outras categorias foram construídas na tentativa de explicar a "pessoa" na organização da sociedade moderna, aparecendo aí um novo elemento, a noção de "igualdade". Para tanto, nosso objetivo é destacar a categoria pessoa e sua gênese teórica. Marcel Mauss construiu um texto, publicado originalmente em 1938, que focaliza o que podemos chamar de construção social da pessoa.

Mauss (1973) ampara sua tese ainda em um esquema que revela progressivamente a pessoa nos elementos modernos, procurando estruturar uma análise contrária aos outros modelos culturais da época.

É a idéia de 'pessoa', a idéia do 'Eu'. Todos a consideram natural, bem definida no fundo da sua própria consciência, perfeitamente equipada no fundo da moral que dela se deduz. Trata-se de substituir essa visão ingênua de sua história e de seu atual valor por uma visão mais precisa (MAUSS, 1973, p. 369).

Marcel Mauss introduziu o debate e contribuiu para o empreendimento geral das formas elementares modernas de compreensão de pessoa. No decorrer do século XX, essa introdução abriu novas perspectivas analíticas e outras tendências de debate no campo das Ciências Sociais e Humanas, tarefa que se constituiu no exercício de amparar as análises sociológicas nas categorias do "pensamento humano" como o próprio Mauss entendia em sua "Conclusão", intitulada "Uma categoria do espírito humano...". Mauss (1973, p. 397) afirmava: "Quem pode mesmo dizer que essa 'categoria', que todos aqui acreditamos estabelecida, será sempre reconhecida como tal? Ela só se formou para nós, entre nós".

Vale ressaltar que, um pouco antes, E. Durkheim (1970) produziu um texto que podemos considerar, sociologicamente, relevante para 
o estabelecimento posterior das categorias 'indivíduo' e 'pessoa', ao discutir uma característica moderna da pessoa: o individualismo ${ }^{1}$. Configurava, assim, o que mais tarde Louis Dumont chamaria de "indivíduo". A antropologia social teve a contribuição da antropologia britânica com Radcliffe-Brown. Com nitidez teórica, RadcliffeBrown expôs com precisão a oposição entre "pessoa" e "indivíduo", em 1940. Para o britânico:

[...] todo ser humano vivendo em sociedade tem dois aspectos: ele é indivíduo, mas também pessoa. Como indivíduo, ele é organismo biológico, um conjunto muito vasto de moléculas organizadas em uma estrutura complexa em que se manifestam, enquanto ele persiste, ações e reações fisiológicas e psicológicas, processo e mudanças. O ser humano como pessoa é um complexo de relações sociais (1973, p. 128).

Tomando esse contexto do antropólogo britânico, o indivíduo se apresenta e se mostra apenas em sua instância calcada na base social, aberto para receber os estatutos sociais. Torna-se evidente que "pessoa" será designada, como no texto de Mauss, uma unidade socialmente condicionada para receber significação.

A partir dos anos 1960, L. Dumont, antropólogo francês, começou a publicar uma série de estudos voltados para explicar os conflitos sociológicos decorrentes da "ideologia do individualismo". Dumont procurou produzir uma teoria da "hierarquia", como estrutura dos sistemas sociais e visões de mundo em que prevalecem representações de "pessoa". Dumont trabalha na conceituação de oposições e tensões, em que cada sistema social é decorrente da complexidade da hierarquia em confronto com tendências ou forças sociais individualizantes que promovem o indivíduo às novas valorações sociais.

\footnotetext{
${ }^{1} \mathrm{~A}$ este respeito consulte-se o ainda significativo "Da Divisão Social do Trabalho". O tema deste livro é central no pensamento do autor: as relações entre os indivíduos e a coletividade. Como pode uma coleção de indivíduos constituir uma sociedade? Como se chega a esta condição de existência que é consenso?
} 
É Dumont (1993) quem nos fornece elementos precisos sobre a noção de hierarquia, quando rompe com conotações de estratificação mais rígidas implicadas no entendimento desta categoria. Dumont a entende como a gênesis pela qual toda experiência sócio-humana (cognitiva e aplicada) dispõe ao indivíduo uma distribuição diferencial do "valor" no mundo, que lhe fornece orientações na situação social que ocupa.

\section{A HIERARQUIA E A NOÇÃo DE INDIVÍDUO: A PESSOALIDADE COMO AUTORIDADE}

Para Louis Dumont (1993), a hierarquia é o "produto" de uma lógica que está baseada na "desigualdade", na qual o "indivíduo" constrói valores a partir de sua individualidade. Afastando esse conceito da relativização do indivíduo, a hierarquia, para Dumont, é tida como um valor e não como uma verdade universal. Trata-se de entender a hierarquia como uma produção moderna, dada pelas lógicas das desigualdades pelas quais o indivíduo se reveste de pessoa.

Dumont concebe o indivíduo, na sociedade moderna, como independente desde a sua origem. Nesse sentido, o indivíduo é colocado numa posição que antecipa as relações sociais e culturais. Se o indivíduo convive e se organiza em sociedade, são dadas a ele, como indivíduo, ideias e noções individuais,

Segundo Dumont, o homem tem a faculdade de construir categorias novas e erigir novos valores. Opor-se ao coletivo é uma nova possibilidade com nova valorização do indivíduo no convívio coletivo. Surgem, portanto, nas posições ocupadas oportunamente, as desigualdades, geradas pela pessoalidade de cada indivíduo. A desigualdade é identificada nos valores adotados e nas posições ocupadas pela pessoalidade de cada indivíduo e passa a agenciar comportamentos adquiridos em seu círculo social/na sociedade.

Ocorre que, quando o indivíduo cria novas categorias e encontra espaços sociais, as igualdades de oportunidades, para que possa ser 
mantida a igualdade de princípios, acabam não acontecendo, gerando, portanto a desigualdade por valores já dados ao indivíduo.

A igualdade de oportunidades pressupõe um pensamento hierarquizante, pois se trata de pressupostos característicos da sociedade em que há relevância da noção de pessoa. Com efeito, cada indivíduo estabelece, em seu meio social, uma ocupação do espaço. Essa noção vem junto com a ideia de que cada um ocupa um lugar no mundo e deve agir de acordo com sua posição.

Assim, a ocupação do espaço não é vista pela determinação do status piramidal e sim horizontal, funcionando como uma fila indiana, onde as diferenciações entre os sujeitos são promovidas pela pessoalidade de cada um, pois, no meio hierarquizante, sempre tem alguém que comanda e alguém que obedece, o que chamamos de precedência hierárquica (LEIRNER, 1997). Nesse sentido, explicando a ocupação do espaço pelo status horizontal, nem sempre a hierarquia obedece aos pressupostos das patentes ou às lideranças de grupo. Uma mesma hierarquia pode estar no mesmo espaço, no entanto há diferenciações entre os indivíduos que o ocupam, seja marcada pela tradição, seja pela pessoalidade dos indivíduos. Essa nitidez hierárquica é própria das instituições que desvelam facetas da hierarquia em que outros domínios poderiam estar imersos com outros fatos. Isso acontece porque :

[...] a hierarquia se revela com suas facetas onde na organização social da instituição ela, hierarquia, se situa no primeiro plano da organização [...]. Portanto a hierarquia implica num principio de gradação dos elementos em relação ao conjunto, ou dizendo de outra forma, numa ordem de precedência, onde uns vêm antes que outros [pois] numa cadeia de comando, passa-se algo semelhante. [...] o que está em 'jogo' são ordens de um lado e obediência de outro [...]. Dois indivíduos - absolutamente iguais entre si - não podem ter entre eles uma relação de mando e de obediência [...]. Percebe-se assim que a hierarquia e a cadeia de comando não são sinônimos, mas que a primeira é condição necessária da segunda (ABREU, 1998). 
Isso vem revelar que, embora existam os panteões hierárquicos semelhantes, procura-se o "experiente", tipificando, nitidamente, um caso de pessoalidade demarcado pela hierarquia horizontal.

Para DaMatta (1997, p. 182), há, no sistema social brasileiro, "[...] uma separação radical e autoritária de duas posições sociais real ou teoricamente diferenciadas", o indivíduo e a pessoa. A primeira expressa o sujeito de leis universais, e a segunda, o sujeito das relações sociais que assume uma identidade posicional que se define a partir da posição que ocupa no quadro social dividido e hierarquizado. Assim, o indivíduo busca formas de ascender à posição de pessoa, fazendo prevalecer seus interesses e usufruindo privilégios, o que DaMatta (1999) denomina de modos de navegação social.

O indivíduo se definiria pela oposição a seu contrário: a pessoa. Esta, por sua vez, se definiria como um ser basicamente relacional, uma noção apenas compreensível, portanto, por referência a um sistema social em que as relações de família, de amizade e de troca de interesses e favores constituem um elemento fundamental. No indivíduo, teríamos, ao contrário, uma contiguidade estrutural com o mundo das leis impessoais que o submetem e subordinam. Desse modo, temos, no Brasil, um sistema "dual" e não um sistema unitário (SOUZA, 2001).

Roberto DaMatta (1990), em "Você sabe com quem está falando?", denota um pensamento hierarquizante da sociedade brasileira. Esse tipo de expressão é característico da sociedade em que há relevância da noção de pessoa. Essa noção vem junto com a ideia de que cada um ocupa um lugar no mundo e deve agir de acordo com sua posição.

Para ilustrar o processo de hierarquia, buscamos um pequeno diálogo com Weber (1982). O autor tece algumas considerações a respeito da burocracia. Baseado em princípios que identifica como originários na ética protestante, ele a define como um sistema de controle social que visa à funcionalidade eficaz das estruturas organizacionais, seja de domínio privado, seja público. De acordo com este autor, a burocracia está calcada em regras impessoais e 
escritas e se dá a partir de uma estrutura hierárquica. Segundo a teoria weberiana, com o advento da burocracia ocorre uma diluição do poder, que deixa de ser centralizado e permanece nas estruturas burocráticas.

\section{CEC: O QUE CONTAM OS DOCUMENTOS}

Antes de analisar os documentos, procuramos nos debruçar na história do clube, fundado em 1940, que permite vislumbrar um cenário de alteridades sociais. O clube se estrutura em um círculo de associados em que o trânsito de sócios se constitui de policiais militares e civis, todavia como nos lembra um dos entrevistados "[...] no clube só não pode ser civil, sendo militar qualquer um pode ser presidente" (A4). Do mesmo modo, as relações de sua administração eram calcadas num único gênero, o masculino, já que o gênero feminino só foi aceito pelas instituições militares, no Brasil, em 1982.

Constatamos, em Foucault (1999), que a via documental percebe os discursos se transformando em tradições, meticulosamente elaboradas, desenhadas, guardando dentro de si um poder, uma hierarquia transplantada das instituições para os menores grupos sociais possíveis. Essa transposição hierárquica se apropria de todos os segmentos de convivência do grupo, na família, no lugar onde se mora e nos clubes que se frequenta, tornando o cotidiano dos agrupamentos completamente hierarquizado. Dessa maneira, percebemos que a tradição, aos olhos de Foucault (1999), permite formar uma coletividade em torno de uma hierarquia invisível, que não ocupa um lugar definido, mas que se dá nas relações.

O documento que avaliza e norteia as condutas, atitudes e disciplina no CEC se encontra estabelecido no estatuto do clube. Trata-se de um documento com 97 artigos, que apresenta implicações diversas nas relações sociais às quais estão sujeitos os associados. É no estatuto do clube que a comunicação da conduta, dos procedimentos, da disciplina se encontram baseadas como produto de um grupo que, legitimado pela coletividade, construiu para disciplinar a convivência dos diversos atores. 
Em 37 dos 97 artigos são descritos os deveres, formas de punição e suspensão, exclusão e readmissão dos associados. É o estatuto que prevê que todos os associados "podem votar e ser votados". No interior do estatuto, os artigos estabelecem direitos e deveres, instituem relações entre os associados e estabelecem as condições dos associados participarem da vida do clube. Dessa forma é possível observarmos que o estatuto do CEC representa, em grande parte, uma cadeia de comandos baseada na ideia de execução, ou seja, a ordem é transformada em ação, pronta para ser acatada. Já os direitos apresentados pelo documento/estatuto partem de uma perspectiva interpretativa, em que as instâncias burocráticas do clube ${ }^{2}$ julgam as possibilidades de direito que cada associado tem. Em síntese, o aparato legal-burocrático do clube cristaliza, no plano teórico, uma dualidade em deveres objetivos e direitos subjetivos. Todavia, como nos revelam as falas dos informantes, havia uma distância entre o documento legal e as práticas cotidianas. Uma evidência disto reside no fato de que, conforme o estatuto, as instâncias burocráticas do clube são autônomas, mas eram de alguma maneira, superadas pela pessoa do presidente. A informação dada por um ator nos diz "Quando você quer alguma coisa você vai direto ao presidente" (A4). Isto nos permite supor que a diluição de poder no aparato burocrático, tal como prevista por Max Weber, não acontece desta maneira neste caso analisado. $\mathrm{O}$ que, de qualquer maneira, reforça a noção de subjetividade dos direitos do associado, uma vez que eles passaram a ser negociados pessoalmente com o presidente do clube.

Os processos das relações estatutárias constroem e redesenham configurações tradicionais. Para tal efeito, chamamos de tradição/ tradicional o que une os homens e dá validade e segurança para o alcance de objetivos. Essas configurações estabelecem e mantêm categorias hierárquicas sobre os indivíduos e permitem a articulação de um poder que se ordena em torno do que é aceito, do que é ou não normal. Em novos desenhos, as configurações tradicionais fazem

\footnotetext{
${ }^{2}$ As instâncias do clube são, conforme o estatuto: Conselho Deliberativo (no qual se encontra a figura do presidente do clube), Conselho Consultivo, Tesouraria, Secretaria, Departamento de Esportes Amador e Profissional e Departamento de Relações Públicas.
} 
aparecer múltiplas ações (verdades já conhecidas), que, por sua vez, produzem e reforçam interpretações, construindo e alimentando crenças e permitindo a continuidade das tradições.

As tradições procedem de uma legitimidade coletiva, que dá sentido ao universo humano e regula as condutas com as quais os homens se ligam, produzem laços e se comunicam. É justamente aqui que a pessoalidade, a figura de quem tem destaque no coletivo é chamada para ocupar os espaços sociais. Essas tradições podem ser sentidas na eleição do Presidente do Conselho Deliberativo (Presidente do clube). No decorrer de sua fundação até 2004, não houve pleito que tivesse dois candidatos.

Podemos dizer neste caso que a figura do presidente do clube entra no cenário social carregando suas condutas pessoais, mas também forte carga simbólica do coletivo legitimador. É por ela que a coletividade será conduzida. Assim, segurança e condutas são sustentadas pela pessoalidade da figura do eleito, e tal como geralmente ocorre no plano formal das organizações militares, ninguém ousa enfrentá-lo. Nessa falta de oposição a essa figura, não há construtos de oportunidade de igualdade distribuídos entre os associados do clube, pois o espaço já foi ocupado. Uma vez ocupado, promove-se uma distinção legitimada, que se encerra na construção de uma hierarquia, aqui entendida como uma relação de identidade e também de distinção criada/construída pelo próprio coletivo e, antes de tudo, um produto dele (coletivo); a hierarquia torna-se uma necessidade.

Por outro lado, isto não deve sugerir que não existam dinâmicas de diferenciação entre a lógica castrense e a organização do clube, para todos os efeitos uma instituição civil. Isto fica mais claro quando observamos que desde sua fundação, em 1940, até 2007, o quadro de associados elegeu 16 presidentes, entre, coronéis, majores, capitães e até mesmo um praça graduado sem divisas hierárquicas. Assim, sua hierarquia não é exatamente homóloga a da instituição militar de origem da maioria de seu quadro associativo. 


\section{Os ESTRETTAMENTOS E A ASCENDÊNCIA PESSOAL}

Como pudemos compreender, neste clube as habilidades relacionadas à prática do futebol e o pertencimento à equipe do clube eram significativas para afetar certas relações sociais. Pertencer ao time profissional de futebol implicava em possibilidades que alteravam as relações hierárquicas entre os associados no clube e na instituição militar. "[...] quando tem jogo importante, pode até ser mudada a sua revista. O clube informa que tal fulano vai jogar e é necessária a presença dele no time [...]". Observamos aqui uma das faces tradicionais tão latentes nas estruturas sociais organizadas e identificadas pela pessoalidade. $O$ jogador deixa de ser um ser do coletivo (indivíduo) e passa a ter ascendência aos espaços hierárquicos (pessoa). Enquanto ao coletivo é dada certa igualdade de tratamento, o jogador de futebol recebe um tratamento pautado na desigualdade, pois se trata de sua individualidade que, no contexto de um clube de futebol, é, antes de tudo, um atributo que desequilibra as relações de igualdade. Assim, as diferenças hierárquicas se tornam ascendentes, de acordo com a condição do jogador de futebol e seu destaque na equipe principal. Porém, as informações traduzidas pelos atores desse período nos indicaram que a relação entre eles era simétrica e não se percebia uma hierarquia que, no campo de jogo, pudesse ser questionada.

Por outro lado, parecia existir significativa circulação dos jogadores de futebol nos outros espaços de socialização do CEC. "Depois do jogo cada um tinha o seu grupo... pessoal do jogo, da bocha, do pagode" conforme nos relataram (A2, A3 e A6). Jogar bem era também um sinal que o jogador poderia transitar em diversos grupos, com espaços já demarcados pela pessoalidade de cada um. Assim, é possível se relacionar com diversos atores.

Não se trata, nesse caso, de um modo de navegação social, mas de relações em grupos. A organização social hierárquica no clube, de alguma maneira homóloga à hierarquia militar era 'quebrada' pelo trânsito dos jogadores de futebol do grupo. Assim revela A4, consubstanciado por A2, A3 e A6: 
[...] quando a gente ficava depois do jogo era chamado pra tomar uma cervejinha... e aí você ficava no meio de capitão, coronel... e se sabe que ninguém vinha... [sem ser jogador de futebol] ninguém se aproximava... deixava a gente lá... e só quando a gente saía [do grupo de coronéis, capitães etc.] é que os outros colegas cumprimentavam pelo jogo... pelo gol do jogo... a gente se dava bem com todo mundo.

É importante notar que, uma vez estabelecida, a hierarquia irá determinar uma inteligibilidade para todo o universo das relações, desde suas relações informais, até sua percepção de mundo. Em outras palavras, ela organiza a possibilidade das relações entre os próprios indivíduos para além da cadeia de hierarquia, obediência e comando. Um dos resultados mais palpáveis são os "círculos hierárquicos", o âmbito de convivência entre indivíduos hierarquizados do mesmo grupo social. Embora as relações objetivem o espírito de camaradagem, cercar o ambiente de estrita confiança, sem prejuízo do respeito mútuo, é uma das premissas dos círculos hierárquicos, pois não se criam relações com nítidas distinções hierárquicas que podem trazer prejuízos mútuos, então o círculo se fecha em detrimento das diferenças individuais.

A ocupação de espaço é decorrente da oposição entre indivíduo e pessoa, na medida em que há "espaços" privilegiados onde cada uma dessas modalidades de relações sociais se concretiza. Parecenos que está claro que, nos grupos em que estamos discutindo, as diferenças se atenuam, o que traz implicações na convivência colocada nas esferas da vida social, pois os valores se justificam e se complementam. Embora não houvesse distinções institucionais, ser jogador de futebol possibilitava, no contexto do clube, relacionarse com outras esferas hierárquicas de valores.

As informações tomam rumos convergentes, quando o questionamento trata de uma posição dos atores nas relações isoladas, individuais, mas não é sentida na mesma proporção, quando um ator responde que 
[...] tinha e até hoje tem. Não só no Caxias, mas em quase todos os clubes, as diretorias têm influência na hora da escalação do jogador. Mas no Caxias todo mundo era igual, podia ser graduado, mas, se não jogasse bola, ficava no banco (A1) ${ }^{3}$.

Naquela época, naquele time não tinha essa de ser graduado, divisa ali, não... A gente era irmão... jogava quem estava bem... e o time sempre entrou em campo unido... Na hora todo mundo era um por cada um... Ô meu filho; em jogo de bola não se bate continência (A6).

Como foi possível compreender, temos o espaço/time de futebol com seu uniforme institucionalizado, cada qual com sua camisa e seu número estampado, revelando sua função, com rigidez de horários, previamente marcados. É a presença da hierarquia de ordem técnica. Não há anonimato dos elementos da equipe, pois cada qual está em seu lugar e sabe o que deve desempenhar previamente, o que garante a presença da pessoalidade. Cada um tem nome e função. Todo esse espaço se contrapõe a um sistema de inclusão, aberto, democrático e generalizado, o qual DaMatta (1990) denomina de festa informal, diríamos, pois, espaço que percebe e domina a forte presença do coletivo.

A partir deste estudo podemos pensar o futebol como um espaço com características de origens coletivas, do indivíduo, no entanto permeado por características fundantes da pessoalidade, da hierarquia.

Aqui estamos tratando do espaço do futebol, espaço que constitui latentes ações sociais, províncias éticas dotadas de positividade, valores, domínios culturais institucionalizados e, por causa disso, espaço capaz de despertar emoções, reações, leis e imagens esteticamente emolduradas e inspiradas (DAMATTA, 1991).

${ }^{3} \mathrm{O}$ caso mais conhecido de influências no futebol brasileiro foi na convocação da Seleção Brasileira de 1970, quando o então presidente E. G. Médici, interferiu na indicação do jogador Dario (Dadá Maravilha). In: ANTERO, L.C. Futebol e ditadura: a história de Nando, o primeiro jogador anistiado do Brasil. Fortaleza: Centro Cultural do Ceará, 2011. 
Para DaMatta (1991), portanto, os espaços, e aqui se reportando aos espaços do futebol, constituem-se de forma antagônica e relacionada, existindo valores e ideias específicos que guiam ou influenciam o comportamento dos agentes em determinada direção, em cada caso. Sabemos também que, para Da Matta, esses valores, no mundo do indivíduo, apontam para uma concepção de mundo impessoal que enfatiza a igualdade e a competição entre iguais, ao passo que, no mundo da pessoa, teríamos o mundo dos sentimentos, do particular, portanto, e de uma hierarquia baseada na afeição (que é sempre gradativa e particularizante).

O que passa, então, a ser imediatamente problemático é explicar a própria possibilidade da existência desses espaços de relação não serem antagônicos, mas complementares.

Cremos ser possível encontrar mecanismos hierárquicos em se tratando da ascendência manifestada nas relações sociais que ocorrem onde há a possibilidade de as fronteiras divisórias serem dirimidas. A hierarquia, aqui atravessada pelo binômio 'individuo/ pessoa' não cria a divisão, ela aproxima as relações. Assim se manifesta um entrevistado: "[...] devido o fato da gente ser militar havia uma concedência [sic] do comando. O comando da PM dava uma condição para que a gente pudesse treinar. No expediente, a gente vinha aqui pro treino, depois voltava pro quartel" (A6). Assim, a pessoalidade estabelecida pelo pertencimento a equipe de futebol criava uma outra hierarquia que, em certo sentido, se reforçava/ apoiava na hierarquia impessoal da instituição militar relacionada. A influência segmentada é hierárquica e transpõe as esferas institucionais. Um ator que esteve no cenário do futebol do clube, na metade da década dos anos de 1970, diz: "[...] às vezes, o presidente do clube era um coronel, tinha facilidade de pedir a liberação de um jogador que pertencia a tal companhia, pra deixá-lo à disposição, liberar o atleta para jogar" (A5).

Estes agenciamentos que deslocavam os jogadores de futebol da condição de indivíduo para a condição de pessoa geravam ainda outras formas de recompensa. Questionados se ser jogador de futebol no contexto dos anos de 1970 garantiria alguma benesse financeira, 
os informantes revelaram que não (A1, A4, A5, A7), contudo tentativas de romper com alguma regra, mesmo teoricamente não institucionalizada, são observadas em estratégias que podem ser julgadas como efeito da pessoalidade. "Quando se tinha que resolver alguma pendência, a gente dava os documentos para o diretor de esportes ou para o presidente do clube e a gente podia ficar tranquilo" (A2). Na fala de A2 e identificada também nos argumentos de A3 e A6, ouvimos que: "Em época de decisão, e quando o campeonato esquentava, não dava tempo de sair por aí resolvendo problema, então a gente dava o que tinha pra resolver pra algum diretor e resolvia".

Como demonstrou DaMatta (1998), esse estreitamento de relações, que permite que as diferenças hierárquicas criadas em diversos espaços, privados, públicos ou pessoais, na sociedade brasileira, sejam contornadas ou manobradas para obtenção de diferenciação é bastante disseminado. Falar com o presidente de forma direta é encontrar caminhos que facultem possibilidade do estreitamento das relações distantes pelos espaços diferentes, mas próximas pelos espaços demarcados pela pessoalidade de jogador e dirigente do clube. Com efeito, as informações obtidas consistem em características que, embora possamos encontrar em outras instituições, aqui os próprios indivíduos as revelam, possibilitando apreender, sobretudo, as diferenças existentes nas relações pessoais e sociais.

\section{AlCANCES CONCLUSIVOS DO ESTUDO}

A partir das investigações deste estudo, constatamos que embora o CEC se estruture como uma organização moderna, organizada pelo seu estatuto e instâncias burocráticas, o contexto das relações sociais permite identificar características tradicionais na solução de situações que são permeadas pela pessoalidade dos dirigentes do clube e dos associados dados pelo viés da habilidade de jogar futebol. Assim, na fala dos jogadores entrevistados, eles se relacionavam em um contexto de desigualdade entre os associados 
demarcados e conquistados pela pessoalidade dos atores em seu desempenho como jogadores de futebol.

A reivindicação de igualdade perante as instituições sociais tem sido uma constância na história da sociedade brasileira. $\mathrm{O}$ caso investigado indica que a conquista de uma cidadania ainda não se expressa nos documentos oficiais/burocráticos, mas as relações sociais entre pessoa-pessoa, é necessária, sine qua non para sentirse atendido e reconhecido. 


Soccer and sociability: traditional and modern
faces of a soccer club
Abstract: The present study analyzed the social
navigability of former soccer players from a
Membership Club mostly consisted of military and civil
policemen. The discussed categories were hierarchy,
person and individual, having Dumont (1993) as
theoretical source. The information for analysis was
collected through open interviews with the club's
soccer players, from 1970 to 1976 . It has been
concluded that the club is structurally organized as a
modern institute with its statute and the bureaucratic,
but exists in a traditional manner. The social
relationships of actors promoted the identification of a
social navigability supported in the person, sponsored
by the performance for having been a soccer player.
Keywords: Soccer.Social. Hierarchy. Persons.
Individuality.

Fútbol y sociabilidad: caras tradicionales y modernas de un club de fútbol

Resumen: El estudio examinó la navegabilidad social de los ex-jugadores de fútbol en un club de asociados, compuesto principalmente de policiales militares y civiles. Se discutieron las categorías jerarquía, persona e individuo, teniendo como fuente teórica Dumont (1993). Las informaciones para el análisis se obtuvieron en las entrevistas abiertas con jugadores de fútbol del club, en el período de 1970-76. Se concluye que el club se organiza de forma estructural como una institución moderna, con su estatuto e instancias burocráticas, pero se mueve de forma tradicional. Las relaciones sociales de los actores les permite identificar una navegabilidad social protegida en la persona, patrocinada por el desempeño ya que se trata de un ex-jugador de fútbol.

Palabras clave: Fútbol. Jerarquía social. Personas. Individulidad. 


\section{REFERÊNCIAS}

ABREU, L. E. L. Meia volta volver: um estudo antropológico sobre a hierarquia militar. Revista Antropologia, São Paulo, v. 41, n. 1, 1998. Disponível em: <www.scielo.br/scielo>. Acesso em: 14 out. 2010.

D'ARAUJO, M. C. et al. Visões do Golpe: a memória militar sobre 1964. Rio de Janeiro: Relume-Dumará, 1994.

DaMATTA, R. Carnavais, malandros e heróis: para uma sociologia do dilema brasileiro. 5. ed. Rio de Janeiro: Editora Guanabara, 1990.

A casa e a rua. Rio de Janeiro: Guanabara Koogan.1991.

O que faz o brasil, Brasil? Rio de Janeiro: Rocco, 1998.

. Brasil: uma nação em mudança e uma sociedade imutável. Revista

Estudos Históricos, Rio de Janeiro, v. 1, n. 2, p. 204-219, 1988. Disponível em: <www.marilia.unesp.br/>. Acesso em: 2 fev. 2011.

DUMONT, L. O individualismo: uma perspectiva antropológica da ideologia moderna. Rio de Janeiro: Rocco, 1993.

DURKHEIM, E. Ciências sociais e ação social. São Paulo: Difel, 1975.

FOUCAULT. M. Arqueologia do saber. 7. ed. São Paulo: Forense Universitária, 2010.

LEIRNER, P. Meia Volta Volver: um estudo antropológico sobre a hierarquia militar. Rio de Janeiro: Fundação Getúlio Vargas, 1997.

MAINGUENEAU, D. Termos-chave da análise do discurso. Belo Horizonte: EDUFMG, 1998.

MAUSS, M. Sociologia e antropologia . São Paulo: Cosac e Naify, 1973.

RADCLIFFE-BROWN, A. R. Estrutura e função na sociedade primitiva. Petrópolis: Vozes, 1973.

SILVA, A. J. Clubes de futebol: esporte memória. Vitória: Prefeitura Municipal, Secretaria de Esportes, 1998.

SODRÉ, N. W. Era o golpe de 64 inevitável? In: TOLEDO, C. N. de (Org.) 1964: Visões críticas do golpe. Campinas: Unicamp, 1997. 
SOUZA, J. A sociologia dual de Roberto Da Matta: descobrindo nossos mistérios ou sistematizando nossos auto-enganos? Revista Brasileira Ciências Sociais, São Paulo, v. 16, n. 45, fev. 2001. Disponível em: <www.scielo.br/scielo>. Acesso em: 25 out. 2010.

TABORDA DE OLIVEIRA, M. A. Educação Física Escolar e ditadura militar no Brasil (1968-1984): entre a adesão e a resistência. Bragança Paulista: EDUSF, 2003.

WEBER, Max. Sociologia. São Paulo: Ática, 1982.

Recebido em: 26.4.2011

Aprovado em: 13.4.2012 
